\title{
Espaços mutantes: da arte de rua às mídias sociais pelo design
}

\author{
Mutant spaces: from street art to social media by design
}

MACIEL, Rosilene Conceição; Mestre em Gestão Integrada do Território; Universidade do Estado de Minas Gerais

rmaciela@gmail.com

ENGLER, Rita de Castro; PhD em Design; Universidade do estado de Minas Gerais

rcengler@uol.com.br

MOURÃO, Nadja Maria; Mestre em Design; Universidade do estado de Minas Gerais

nadjamourao@gmail.com

ROSA, Manoela Tarcila Martins; Design de Produto; Universidade do estado de Minas Gerais

\section{Resumo}

O cenário urbano está sujeito a novas apreensões e disputas constantes de interesses e lutas semânticas que o modificam do ponto de vista concreto, mas também conceitual, intelectual. Este artigo apresenta o resultado de um projeto extensionista, com o objetivo de monitorar a transformação da paisagem urbana pela arte popular de rua. Sob o ponto de vista do design, o projeto propõe uma ação mediadora com o objetivo de desenvolver, aprimorar e divulgar uma ferramenta colaborativa de registros de imagens das manifestações culturais urbanas realizadas no Viaduto Santa Teresa e entorno, no baixo centro de Belo Horizonte. Como metodologia, buscou-se documentar as diferentes manifestações e intervenções que acercam o espaço por meio de registro fotográfico, monitorar as transformações periodicamente e após análise comparativa, divulgar em página própria nas mídias sociais, proporcionado espaço aberto para colaboração e discussão.

Palavras Chave: design; arte de rua; mídia social.

\begin{abstract}
The urban scenario is subject to a new perception and search of interests and semantic struggles that modify the concrete, but also conceptual, intellectual point of view. This article presents the result of an extension project, with the objective of monitoring the nature of street art. The project design is a mediating action with the objective of developing, improving and disseminating a series of collaborative records of the urban cultural manifestations carried out in Viaduto Santa Teresa and the surrounding area, in downtown Belo Horizonte. As a methodology, we tried to document the different manifestations and interventions that approach the space by means of photographic registration, monitor the transformations periodically and after comparative analysis, to divulge in own page in the social media, provided open space for collaboration and discussion.
\end{abstract}

Keywords: design; street art; social media. 


\section{Introdução}

Este trabalho propõe uma aproximação das discussões acadêmicas às manifestações urbanas, no sentido de registrar as ações de arte e design expressas nas ruas da cidade e dar a elas maior visibilidade, alcance e reflexão acerca dos significados estéticos, subjetivos e ideológicos que carregam. Entende-se que o registro e difusão das manifestações urbanas é uma maneira de expandir a visibilidade das mesmas para além daqueles que transitam no local, amplificando as vozes de quem as gerou proporcionando a apreensão e compreensão em escala ampliada.

O espaço urbano pode ser ressignificado pelos seus usuários e frequentadores, sendo o próprio cidadão, detentor da visão de valorização ou depreciação do mesmo. "Tomada pelo indivíduo, a paisagem é forma e aparência. Seu verdadeiro conteúdo só se revela por meio das funções sociais que lhe são atribuídas no desenrolar da história" (LUCHIARI, 2001, p. 13). Tanto o artista quanto o designer, ao interferir nestes espaços, comunicam ideias, promovem reflexões e contextualizam a paisagem urbana a partir dos cenários culturais, políticos, sociais.

A maneira como se utiliza o espaço comum é um fator que irá Ihe atribuir novos valores e significados, criando relações de territorialidade e identidade que são expressas de formas variadas e percebidas também de diferentes maneiras de acordo com o repertório e experiência do observador. Essas definições e delimitações ocorrem tanto de maneira física e concreta quanto de forma simbólica, alterando e transformando constantemente a paisagem urbana local. Embora a paisagem seja apenas um fragmento da configuração territorial, sua valorização, seleção ou repulsão pela sociedade também orientam o imaginário social na organização de territórios (LUCHIARI, 2001, p. 11).

A área sob o Viaduto Santa Teresa e proximidades (Rua Aarão Reis e Praça Rui Barbosa), na região central de Belo Horizonte/MG, foi escolhida como campo de observação neste trabalho por apresentar uma significativa importância política e cultural na cidade decorrente da última década, sendo palco de grandes manifestações políticas, artísticas e culturais, ganhando importância política e cultural, que reflete no cotidiano e no movimento da cidade. Novos olhares se lançaram sobre a arte e todo o contexto sócio político cultural que se lançara ali. E a diversidade de expressões artísticas surgiu como necessidade de expressão e apropriação de um ponto significativo da cidade. Concentram-se ali lambe-lambes, picho, grafite, pequenas intervenções e grandes painéis que podem ser vistos pelo transeunte que se desloca pela região, principalmente aquele que anda a pé.

A efemeridade destas manifestações motivou um projeto extensionista que propunha registrar periodicamente as imagens do local como forma de gerar um acervo e de divulgar as imagens via redes sociais. A proposta era criar uma plataforma colaborativa para que artistas, designers e admiradores deste tipo de trabalho se manifestassem postando imagens e suas impressões sobre elas, sobre o local e a relação existente com a realidade daquele espaço, que até então, havia sido marginalizado e desprezado pelo poder público e pela população em geral, prestando-se a abrigo para moradores de rua e outras ocorrências associadas às drogas e violência.

Na perspectiva de ampliar a visibilidade da transformação do lugar e de mostrar a arte que se instalou naquele território, o espaço das redes sociais de comunicação mostrou-se um canal a ser explorado a fim de potencializar o alcance desse movimento. Traçou-se como proposta a estruturação e promoção de um ambiente virtual que possibilitasse o compartilhamento de 
conteúdo imagético e textual acerca das intervenções gráfico-visuais realizadas na região delimitada para o estudo. Entendendo que o papel do designer não se restringe ao planejamento e uso da ferramenta de comunicação, mas também no entendimento e mediação das manifestações, ou ele próprio o autor de projetos de intervenção no espaço urbano.

A proposta do projeto apoiou-se na ideia de que no contexto das paisagens urbanas, o deslocamento da arte de rua para o universo das redes sociais, poderia tornar ainda mais mutante a dinâmica da expressão artística popular carregada de conteúdos simbólicos associados à vida, à cultura como um reflexo do território e da cidade. Visava ainda, a construção de um acervo e possibilitar que as pessoas registrassem suas percepções sobre as intervenções que acontecem no território físico, contribuindo para a dinâmica na percepção e construção de identidades destes espaços, da própria cidade e da arte produzida naquele contexto: manifestações culturais, fortemente relacionadas ao território e à comunidade que os produz.

Nesta direção, trabalhou-se para o desenvolvimento, aprimoramento e divulgação de uma plataforma colaborativa de registros de imagens e vídeos das manifestações culturais urbanas em espaços públicos, no baixo centro de Belo Horizonte, buscando ampliar a visibilidade, possibilidade de interação e troca de olhares e percepções sobre a constante movimentação cultural que modifica a paisagem urbana.

Especificamente, foram definidas como metas: lançar um espaço virtual em mídia social, abastecida por registros de usuários, frequentadores e agentes ativos da transformação local; promover a participação dos atores que vivenciam o espaço; cuidar da constante atualização de dados; proporcionar visibilidade às ações e manifestações expressas e impressas no local.

Partiu-se da ideia de promover a expansão do território físico possibilitando que a sua identidade, já consolidada pelos seus usuários, tivesse visibilidade também por meio do ambiente virtual, ampliando assim o alcance das manifestações de rua. Dar a conhecer, incitar e provocar, nos mais variados públicos o desejo de participar de forma mais efetiva ou circular pelos espaços públicos da cidade.

Partiu-se da premissa de que os espaços digitais permitem a discussão aberta, e podem proporcionar a participação da sociedade sobre os assuntos que acercam, no caso, um território específico. Podem funcionar como ferramentas de interação entre os usuários e o objeto, sendo o designer um possível moderador dessa dinâmica. Falcão (2014) defende que a função do designer é, também, atuar no desenvolvimento de situações propicias para o surgimento de novos significados, considerando a relação do usuário com o objeto e, de forma intencional, o pensamento da experiência projetada. Ao atuar no cenário de compartilhamento de conteúdo, as plataformas trabalham em conjunto com as redes sociais como Facebook, Instagram, Twitter, blogs dentre outras interligadas, integradas e visualmente conectadas. No caso deste trabalho foram testados os dois primeiros.

\section{Desenvolvimento e metodologia}

O projeto desenvolveu-se dentro da proposta inicial apresentada, passando por pequenas adequações para ajustar-se melhor aos objetivos. No decorrer do processo, observou-se que seria necessário abranger uma área menor do que a proposta, de modo que otimizasse a captação e organização do conteúdo. Trabalhou-se em duas vertentes distintas, porém complementares: pesquisa bibliográfica e registro fotográfico in loco; gestão do conteúdo on-line. 


\subsection{Fase 1 - Pesquisa e mapeamento}

A pesquisa iniciou-se a partir de revisão bibliográfica acerca do contexto que fez com que o espaço público comum se tornasse um lugar dotado de significado e valor, criando laços de identidade e territorialidade com seus usuários e frequentadores. Posteriormente, os estudos se voltaram para uma temática mais específica, que embasava a criação de um espaço virtual, como uma extensão digital do território físico, possibilitando a troca de informações e conteúdo em diferentes níveis.

A primeira visita ao local teve como objetivo reconhecer o campo e gerar os primeiros registros fotográficos. Mediante análise do material produzido, foi tomada a decisão sobre quais seriam os pontos de atuação para os futuros registros. A área de estudo para acompanhamento foi restrita a uma pequena porção da Rua Aarão Reis (fig. 1): fachada dos números 542 e 554 (Área 1 - A1), área sob o Viaduto Santa Teresa (Área 3-A3) e a quadra de basquete anexa (Área 2-A2). A seleção desses pontos deu-se pela identificação dos mesmos como pontos nodais da produção cultural e da arte urbana local.

Figura 1 - Locais de Estudo

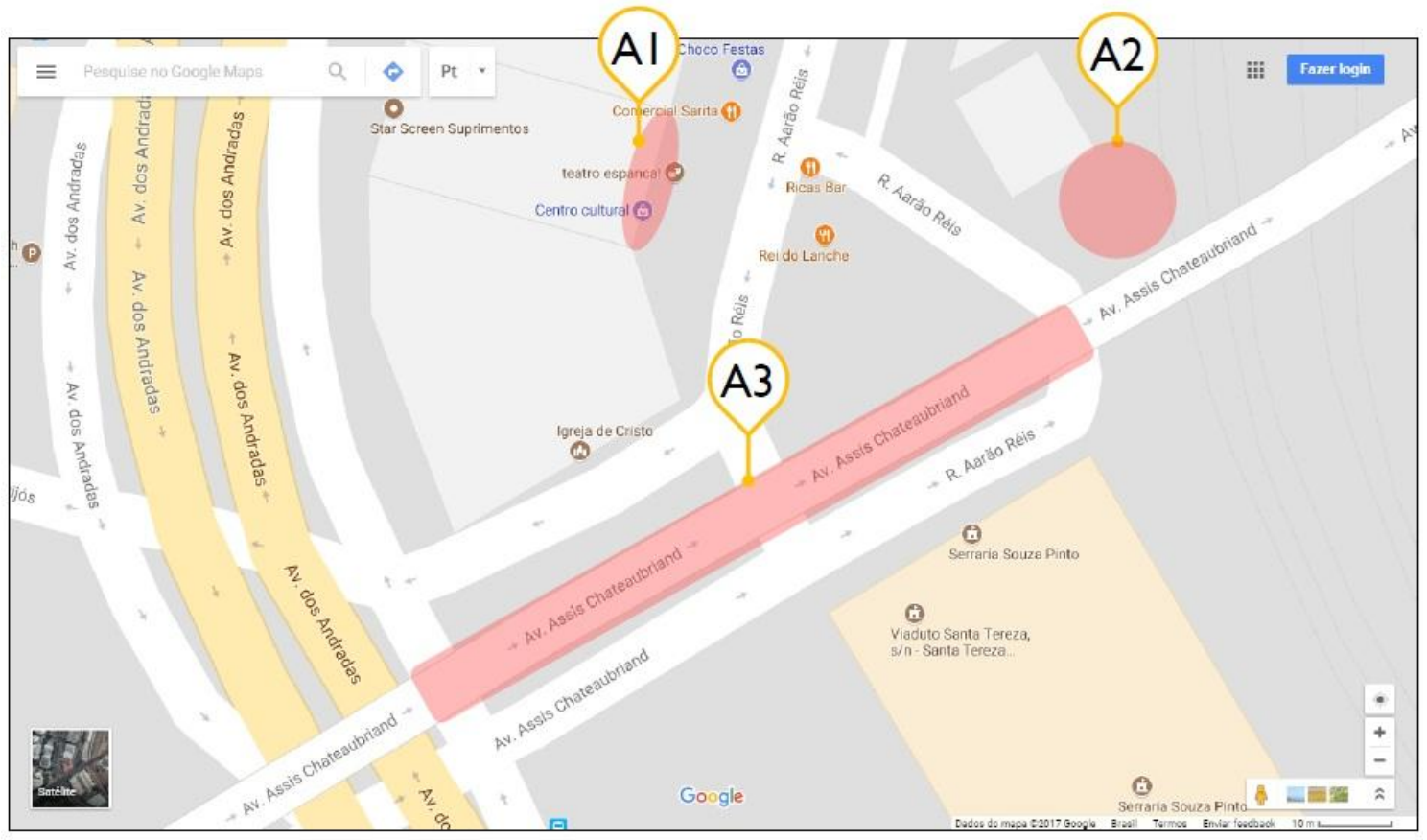

Fonte: Elaborado pelos autores adaptado do Google Maps (2017)

As áreas selecionadas foram fotografadas em diferentes datas, onde a abordagem adotada era de se manter os ângulos de registro os mais similares possíveis. Desse modo, tornou-se viável a geração de um banco de imagens que servisse de material comparativo entre si posteriormente.

\subsection{Fase 2 - Desenvolvimento e produção}

\subsubsection{Registros fotográficos}

No período entre Junho/2017 e Outubro/2017, foram realizadas visitas periódicas (entre 15 e 20 dias) em campo para captura de imagens. A primeira delas diz respeito ao reconhecimento 
de campo. Todas as demais seguiram um padrão ditado pelo mapeamento esquematizado. As fotos realizadas na região sob o viaduto seguiram a ordem alfanumérica crescente e em sentido horário ao que foi determinado pelo mapa. Assim, foi possível organizar e catalogar o material gerado para posterior análise comparativa das mudanças registradas de um mesmo ponto. Os registros não se restringiram apenas às localidades citadas e mapeadas, havendo ocasiões onde eram também geradas imagens da fachada dos prédios próximos, a exemplo da Serraria Souza Pinto, do palco e também do painel posterior, ambos sob o viaduto. 0 objetivo era abarcar o maior número de informação visual possível que viabilizasse traçar algum paralelo entre os locais e suas respectivas mudanças, similaridades e paradoxos.

\subsubsection{Organização/catalogação das imagens}

As imagens geradas em forma de arquivo foram renomeadas, recebendo a identificação do pilar e face ao qual pertenciam, adicionando também a informação da data em que foi gerada. Foram criadas pastas com a identificação do local ao qual pertenciam e nelas foram depositadas as respectivas fotos.

\subsubsection{Ação promovida 1: Matéria Optativa "Território, Tradição e Inovação"}

O projeto de extensão foi associado ao ensino por meio da disciplina optativa "Território, Tradição e Inovação", devido ao estudo das identidades territoriais. Foi feito então a esses alunos, um convite para que visitassem o local de estudo e gerassem seu próprio conteúdo a respeito, dentro da temática abordada pelo projeto, para que posteriormente fosse compartilhado, tornando-os colaboradores da plataforma. Assim, foi realizada uma atividade externa em campo, onde em um primeiro momento se apresentou o histórico do lugar associado à fundamentação teórica seguidas de discursões acerca da temática territorialidade, identidade e produção cultural. Em um segundo momento os alunos saíram em observação registrando as imagens em fotografias. Os registros efetuados pelos alunos foram posteriormente compartilhados como conteúdo imagético e textual na página do Facebook ${ }^{2}$ administrada pelos integrantes do projeto.

\subsubsection{Ação promovida 2: Roda de conversa}

Foi realizada como parte do projeto uma roda de conversa ${ }^{3}$ cujo tema fora "Intervenção e arte no Viaduto Santa Tereza". Como convidados para o debate, contou-se com a participação de artistas de rua como a Krol da Crew Minas de Minas (grafiteira integrante da $\mathrm{Crew}^{4}$ Minas de Minas, o primeiro grupo de grafite da América Latina formado apenas por mulheres), Felipe Arco (considerado um pichador poeta, escreve frases de poesia em diversos pontos de Belo Horizonte) e Raquel Bolinho (criadora do Bolinho, famoso personagem de grafite de Belo Horizonte com mais de 600 Bolinhos grafitados nas paredes, muros e viadutos da capital).

O objetivo foi discutir a diversidade das intervenções no espaço, resgatar um pouco da trajetória de ocupação e apropriação do viaduto Santa Teresa e seu entorno, as identidades e territórios que se sobrepõem. As "disputas" simbólicas e territoriais. As relações com a cidade. 0

\footnotetext{
${ }^{1}$ Disciplina proposta e ministrada na Escola de Design aberta a todos os cursos de Design e Artes Visuais, $2017 / 2$.

${ }^{2}$ Muros espaços mutantes - https://www.facebook.com/MUROSespacosmutantes/.

${ }^{3}$ Roda de Conversa proposto pela professora Rosilene Maciel e os alunos Manoela Tarcila, e Kawany Tamoyos, que atuou também como mediadora junto ao professor Wagner Rossi em parceria com o Núcleo de Design e Cultura do Centro de Extensão da Escola de Design /UEMG" em 25 de outubro de 2017.

${ }^{4}$ Crew é um termo específico da rua que denomina um grupo de grafiteiros.
} 
alcance (cultural, social e político) dos manifestos. Discutiram-se também as possibilidades de atuação do design como mediador no processo de ampliação da visibilidade das manifestações artísticas por meio das mídias sociais e de sua atuação nos painéis de rua, lambe-lambes e outros. $\mathrm{Na}$ oportunidade, apresentou como pauta de discussão a proposta do projeto de gerar uma plataforma colaborativa para registro das diversas formas de arte manifestas no viaduto Santa Teresa e entorno, a importância de se construir um acervo de imagens para difusão das manifestações gráfico-visuais de rua como fonte de conhecimento, estudos e pesquisas futuras.

$\mathrm{Na}$ ocasião os convidados compartilharam suas experiências artísticas e a relação criada com o Baixo Centro e Viaduto Santa Teresa. Falaram sobre seus trabalhos realizados na região e expressaram suas perspectivas pessoais. Quanto à plataforma colaborativa ou redes sociais como uma forma de construção de acervo ou registro, os artistas se colocaram contra no sentido de que a arte de rua é para ser apreciada no ambiente urbano, como uma galeria aberta, e não nas redes sociais. Entendem que a arte deve ser fruída no local, no contexto do território urbano pela ligação com o espaço, com o lugar, com as pessoas e com a realidade sociocultural. Foi um debate importante no processo que, de certa forma, redirecionou em parte o trabalho de extensão e pesquisa em relação à proposta de perpetuação das intervenções urbanas em meio virtual.

Foi um debate definitivo que respondeu ao primeiro ponto abordado na introdução deste artigo: aproximar as discussões acadêmicas às manifestações urbanas. Neste momento, a academia abriu o espaço para receber os artistas de rua para um debate, em uma escola de design, que por sinal, teve grande adesão e interesse por parte dos alunos que em muitos casos, atuam nos espaços urbanos. O tema é atual e pulsa na cidade. Pulsa também nos muros da Escola de Design. Está relacionado às artes, ao design e a outros campos nas esferas social, cultural, política. As iniciativas acadêmicas, de pesquisa, ensino e extensão precisam mesmo dialogar com o seu entorno, com a cidade, com a rua, sob pena de incorrer em idealizações descontextualizadas mesmo atuando na direção de questões relevantes.

A partir deste momento, o projeto assumiu novas diretrizes e buscou adequar à proposta entendendo que era necessária uma mudança nos objetivos. Manteve-se o propósito de gerar o banco de imagens, os registros periódicos e as análises comparativas com foco na diversidade das manifestações e sua efemeridade. Manteve-se o objetivo de contribuir para a geração de um acervo, colaborando para a história do lugar e para uma análise das manifestações ao longo do tempo sob o ponto de vista da arte e do design. A efemeridade deste tipo de intervenção motiva uma nova forma de contar esta história, e compreendê-la sob diferentes pontos de vista, especialmente no futuro, distanciados do nosso tempo.

\section{Discussão e Resultados}

Na primeira visita ao local para registro das imagens, reconhecimento pormenorizado do campo e definição de estratégias de trabalho, um rico cenário e amplo universo para estudo se mostrou aos pesquisadores. Além das dimensões em termos de espaços a serem percorridos, registradas e monitoradas, deparou-se também com uma riqueza de detalhes que se perderiam em um trabalho que tentasse abarcar uma grande área considerando o tempo disponível para a realização do projeto.

Diante desse cenário encontrado no entorno do Viaduto Santa Teresa e dos objetivos traçados, a área de estudo foi repensada e reduzida. Esquematizou-se um mapeamento para que fosse possível acompanhar as mudanças realizadas nos pontos com maior volume de intervenções 
gráficas e que possivelmente, sofreriam alterações ao longo do período analisado (fig. 2). Os pilares foram os pontos selecionados para essa estratégia por se tratar de estruturas físicas que possibilitariam melhor organização e controle do conteúdo gerado além de apresentarem uma diversidade de intervenções (grafites, lambe-lambe, estêncis e pichações) em menor escala dimensional.

Figura 2 - Mapa de Identificação dos elementos: numeração dos pilares e indicação das faces

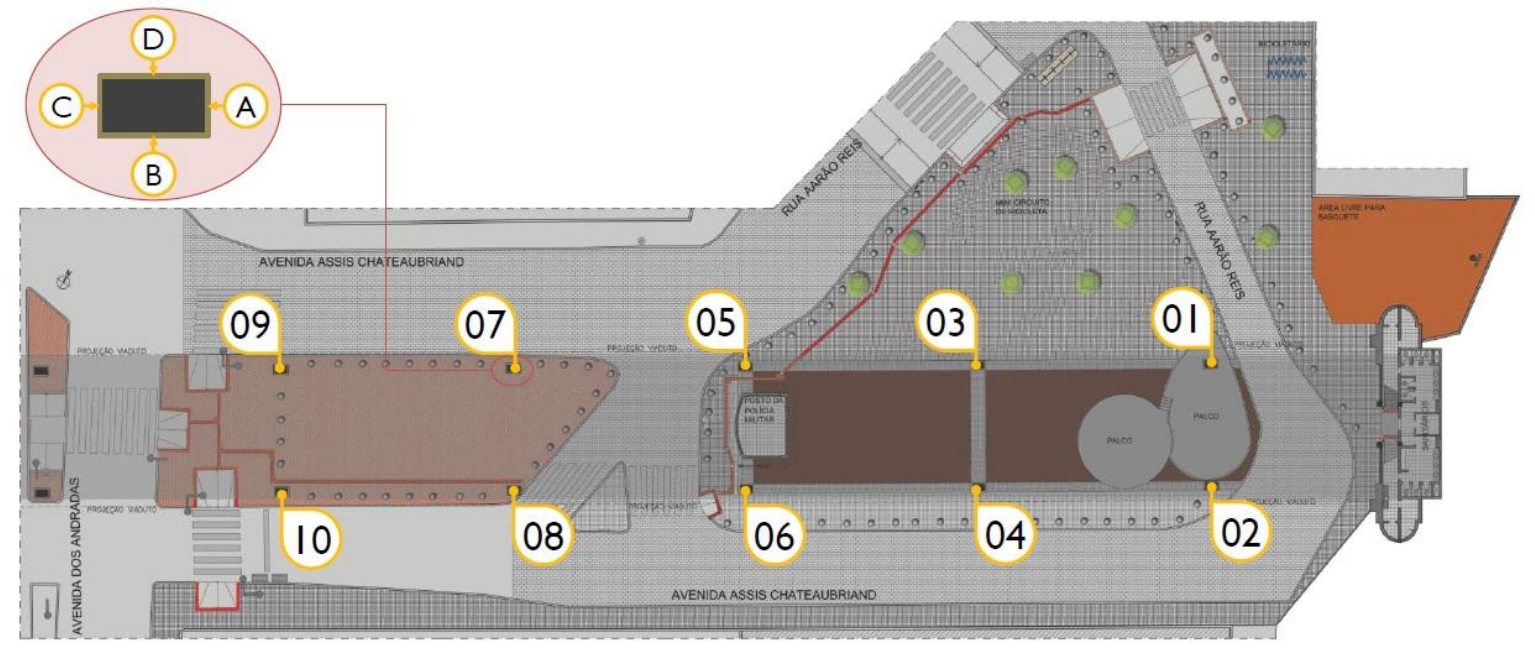

Fonte: Elaborado pelos autores (2017)

Como demonstrado acima, os pilares foram numerados (de " 01 " a " 10 ") e cada uma de suas quatro faces identificadas por uma letra ("a", "b", "c" ou "d"). Nas figuras abaixo, imagens do entorno do viaduto Santa Teresa. Os resultados alcançados podem ser divididos em duas esferas: do material produzido a partir dos registros realizados para análise comparativa; e das plataformas para compartilhamento de conteúdo e informação.

\subsection{Registros de imagens}

Como sinalizado no mapeamento (fig.1), três pontos foram selecionados para a realização dos registros periódicos. As imagens a seguir mostram estes pontos que correspondem às fachadas dos estabelecimentos localizados à Rua Aarão Reis entre os números 542 e 554 (Área 1 A1), a quadra de basquete anexa (Área 2 - A2), e a área sob o Viaduto Santa Teresa (Área 3-A3).

Figura 3 - A1: Rua Aarão Reis em 16/08 / A2: Quadra anexa
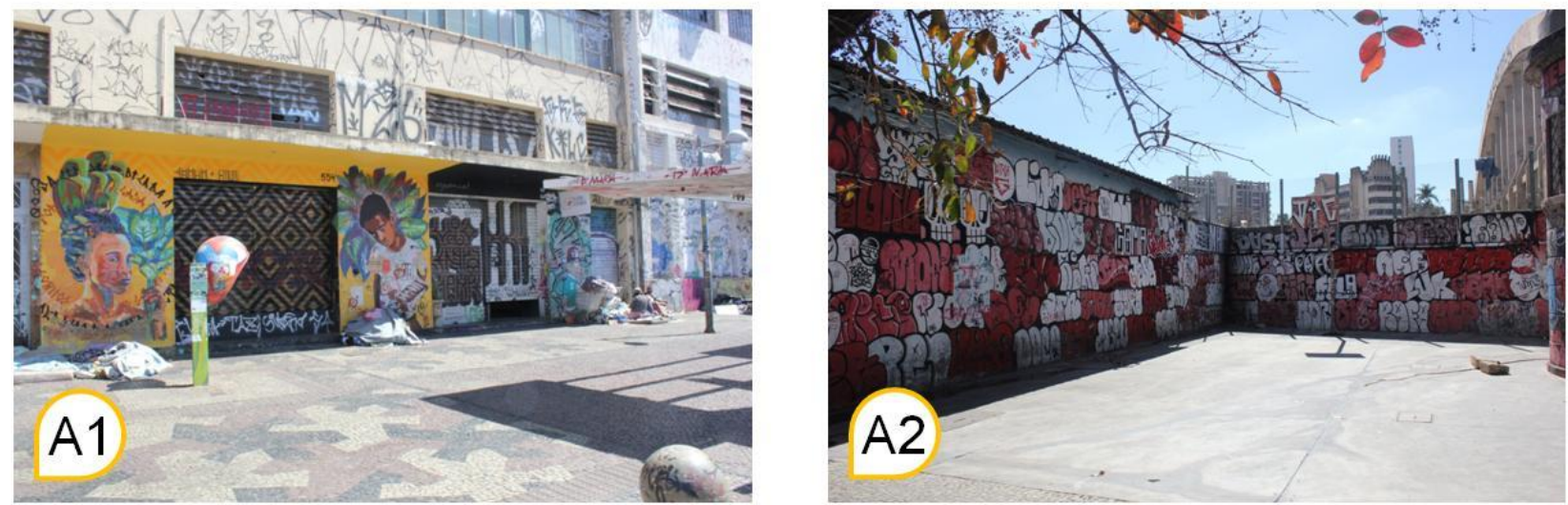

Fonte: Acervo de pesquisa (25/08/2017). 
Figura 4 - A3: Área sob o Viaduto Santa Tereza

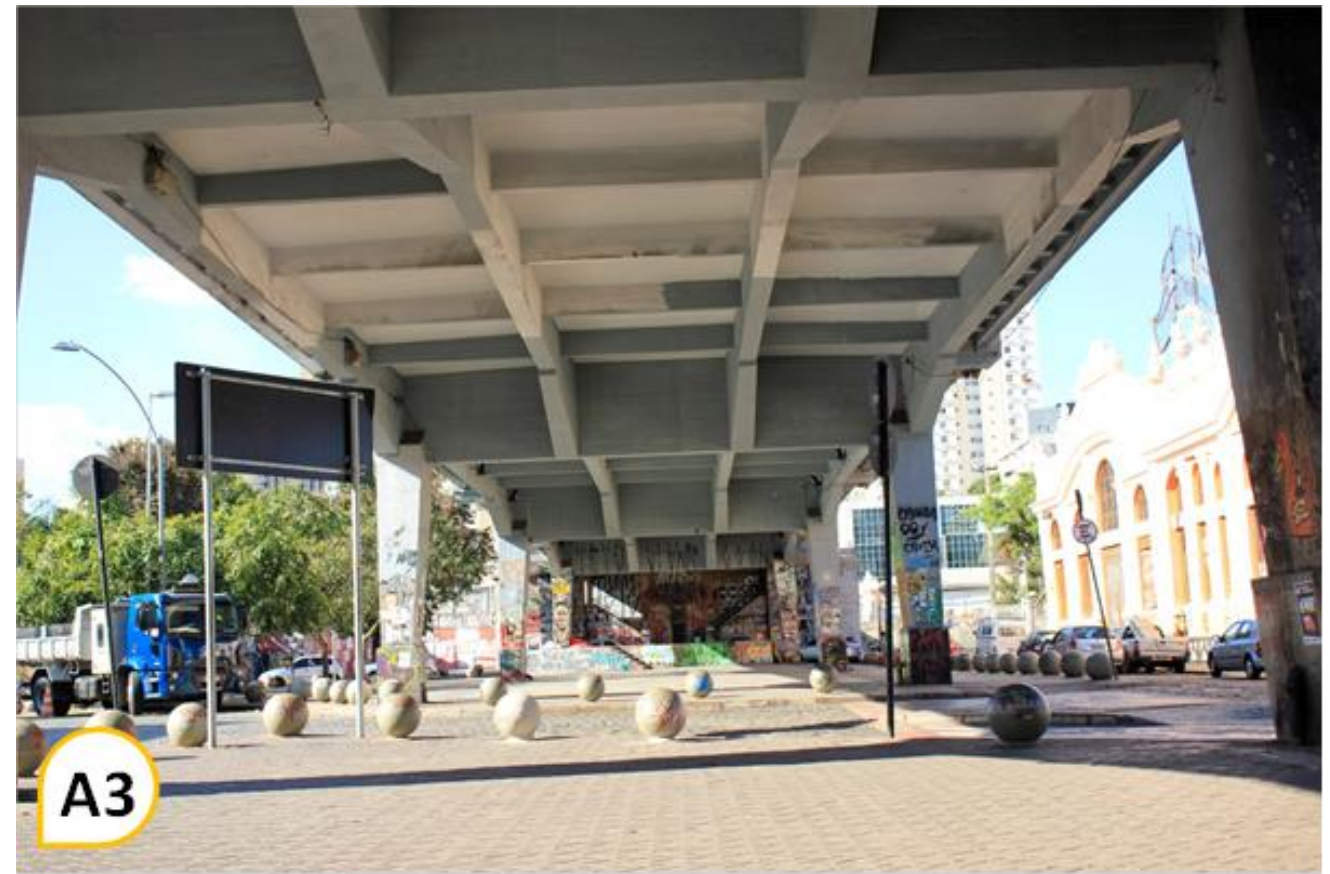

Fonte: Acervo de pesquisa (12/07/2017).

Esta área, A3, sob o viaduto, é o maior espaço e é onde ocorrem as mais diversas manifestações em geral. Eventos programados e atividades espontâneas ligadas à música, à dança, ao teatro e ao esporte dentre outras.

As imagens a seguir, exemplificam parte do trabalho, mostrando um comparativo entre os registros fotográficos realizados. Duas datas foram selecionadas para ilustrar o monitoramento das intervenções: 12/07 e 06/10 do ano de 2017. Dos pilares registrados, os que mais apresentaram maiores alterações foram os de numeração 01 e 02, em função da sua proximidade ao palco em que ococrrem o evento cultural "Duelo de MC's". Nesses eventos, novos graffites são realizados sob a supervisão dos produtores do próprio evento.

No pilar 1, é possível perceber a sobreposição visual na face B onde foi inclusive deixado parte do desenho anterior, as asas sobre o fundo azul, na parte superior do pilar. Na face C, em menor proporção, houve também uma sobreposição parcial na parte inferior mantendo parte do trabalho anterior em balão com fundo amarelo e texto na cor preta. As demais faces, possuem também interferencias mas de pequenas dimensões que não serão mencionadas aqui.

No pilar 2, é interessante observar que há resquícios de mais de um trabalho sobreposto. A parte superior em fundo preto com picho parece ter sofrido uma interferência marcada por um contorno em amarelo um pouco mais abaixo; que por sua vez foi sobreposta por ilustração de um pernonagem com um microfone na mão e fundo azul que cobre até uma certa parte logo abaixo do contorno em amarelo. Isso foi possível observar no registro fotográfico do dia 12/07. $\mathrm{Na}$ imagem do dia 06/10, observa-se outras duas intervenções sobrepostas: uma em texto verde ocupando quase toda a área e outra no canto inferior esquerdo ambas com características da escrita do picho. Com isso pode perceber a dinâmica de apropriação do espaço e diversidade estética e conceitual nas intervenções. 
Figura 5 - Pilar 1: Registros perídicos dos pilares
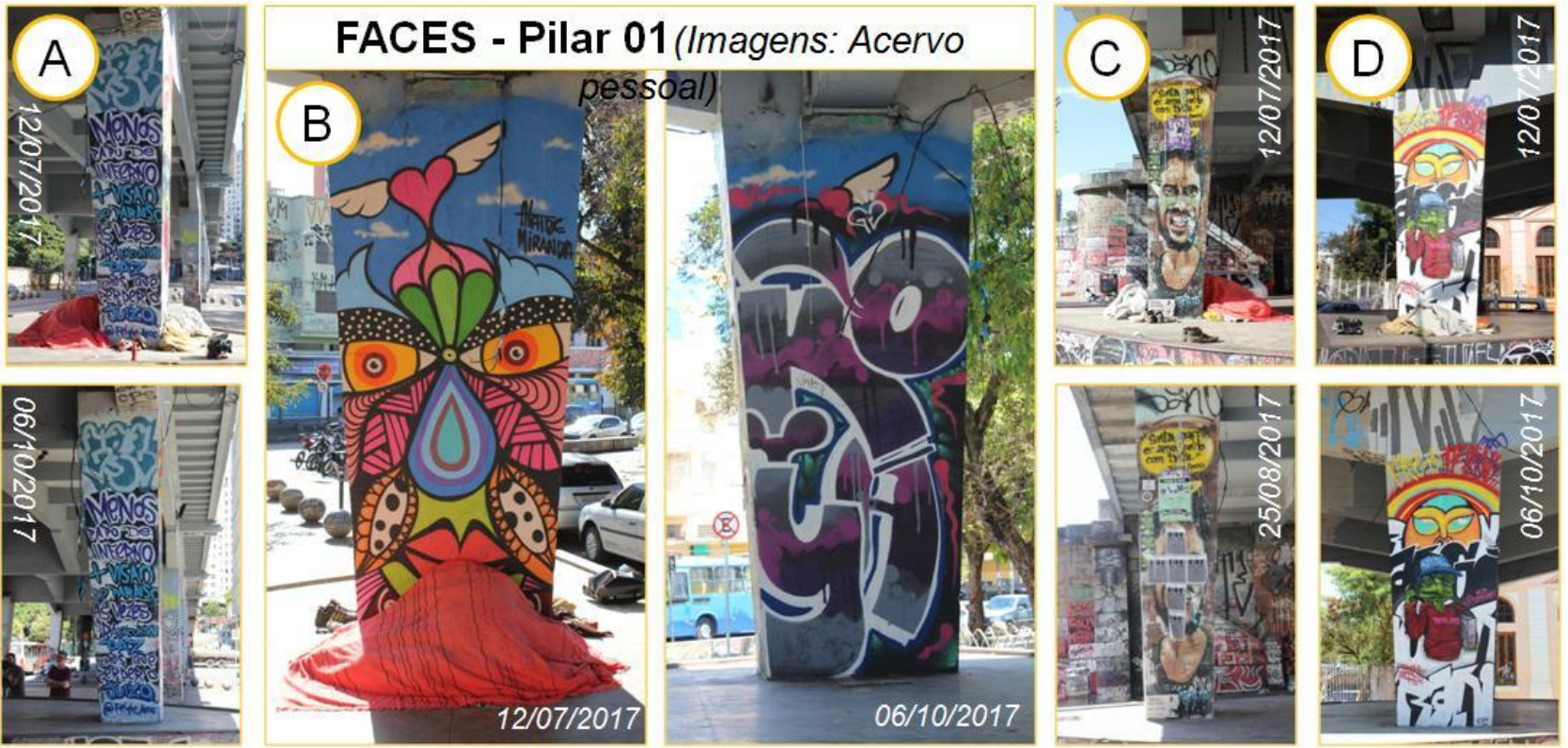

Fonte: Acervo de pesquisa (2017).

Figura 6-Pilar 2: Registros periódicos dos pilares
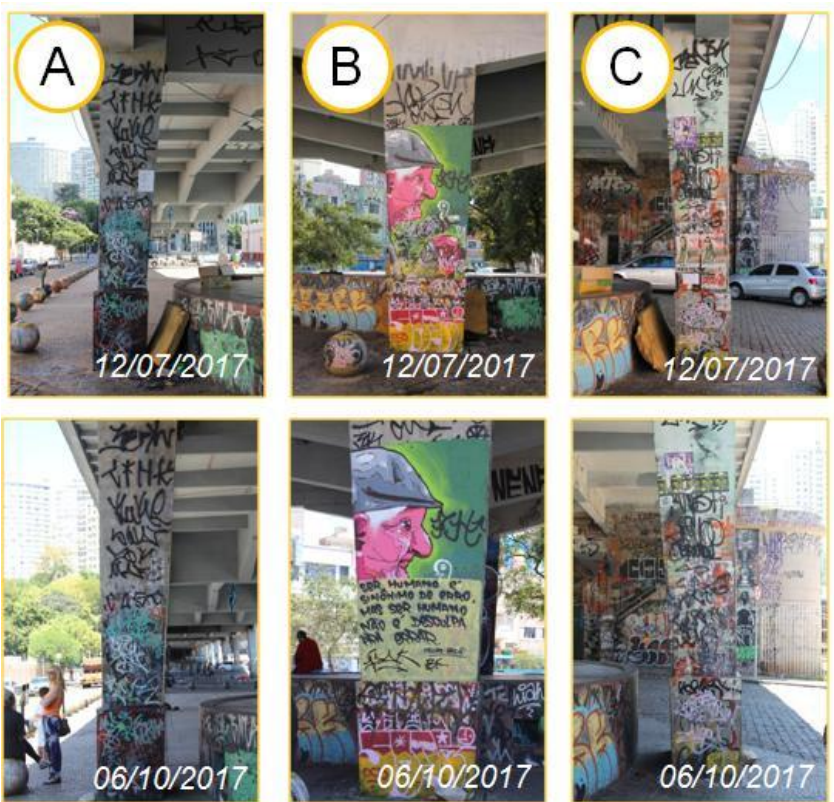

\section{FACES - Pilar 02 (Imagens: Acervo}

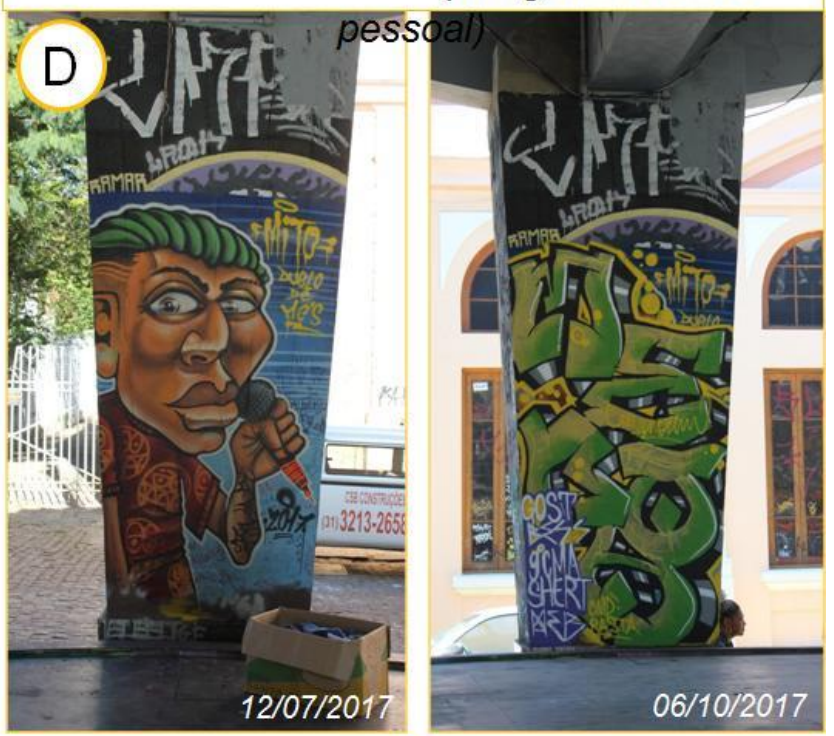

Fonte: Acervo de pesquisa (2017).

Interessante observar que esta prática é comum e muito aceita entre os artistas. A arte de rua é caracterizada por sua efemeridade e pelas intervenções que podem implicar em completude ou mesmo contraposição política, ideológica ou simplesmente pelo uso do espaço como suporte para a manifestação. 


\subsection{Página “Muros - Espaços Mutantes"}

O conteúdo obtido no trabalho de campo foi organizado por áreas e pilares definidos para as análises. Mesmo com a mudança na estratégia do trabalho, pós-debate com os artistas, manteve-se a ideia da página em mídia social, inicialmente criada como ponte para uma plataforma colaborativa. Hospedada nas redes sociais Facebook ${ }^{5}$, a página conta com uma breve descrição do trabalho e seu objetivo.

Figura 7 - Página "MUROS - Espaços Mutantes"

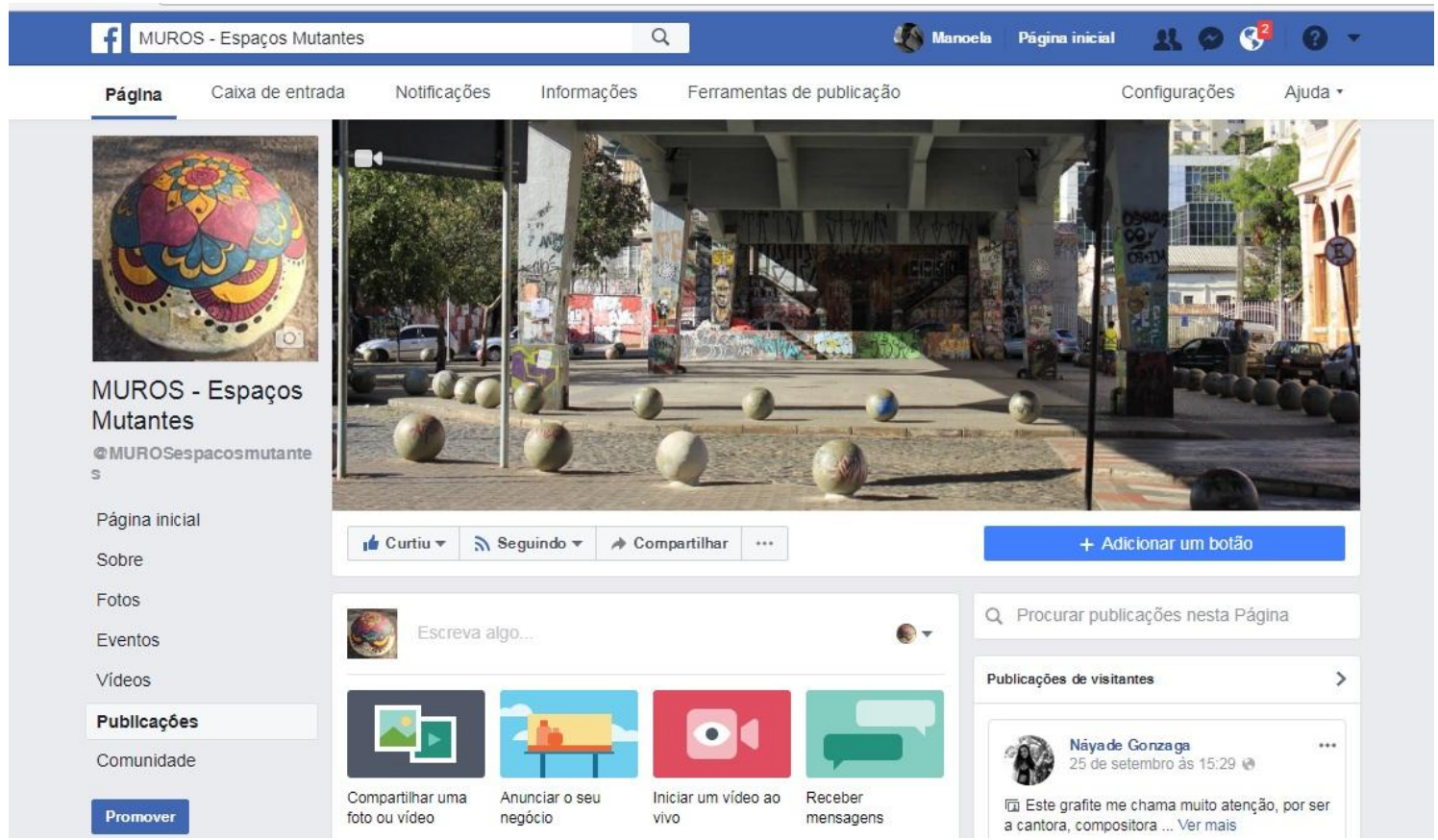

Fonte: https://www.facebook.com/MUROSespacosmutantes/ (2017).

Nela foram divulgados alguns dos registros realizados (selecionados previamente) como demonstração do objetivo proposto. Inicialmente, foram postados conteúdos gerados pelos pesquisadores envolvidos no projeto como moderadores de conteúdo, como um convite aos demais usuários da página. Enquanto página aberta/pública, os seguidores podem compartilhar conteúdo próprio relacionado ao tema, descrevendo as circunstâncias em que foi realizado o registro postado, tendo como base a tríade: data, local e contexto. Almeja-se que futuramente, não seja mais necessária essa moderação, impulsionando autonomia da página, mesmo diante do entendimento que se trata de um processo a ser trabalhado em conjunto com usuários.

\section{Considerações}

Este trabalho apresenta o encontro da Arte urbana e a (re)construção do imaginário da cidade, que é recriado constantemente. Assim, uma forma de monitorar as transformações periodicamente, proporcionando um espaço aberto para colaboração e discussão na mídia, é o diferencial neste trabalho, pois permite discussões, trocas de experiências, divulgação dos

\footnotetext{
${ }^{5}$ MUROS espaços mutantes. https://www.facebook.com/MUROSespacosmutantes/
} 
trabalhos dos artistas e também uma oportunidade, um espaço aberto para as pessoas que são admiradoras da arte urbana.

Mediante a dinâmica proposta no projeto, iniciou-se a construção de um banco de imagens autorais onde o colaborador da página pode expressar sua relação pessoal com a arte de rua e, especificamente, com as intervenções artísticas manifestas no viaduto Santa Teresa e entorno. Conteúdo este que quando compartilhado possibilita discussões, trocas de experiências, embates de posicionamentos de artistas e admiradores da arte de rua.

Os registros fotográficos realizados foram utilizados para o lançamento de página em mídia social. Tal como nos mapas colaborativos, almeja-se uma relação que possa se estabelecer em meio à reciprocidade, onde os indivíduos possam prover novos dados dentro de um determinado contexto, capazes de transmitir também sua própria perspectiva.

A criação do banco de imagens e a manutenção da página visam também à criação de um acervo para futuras análises e estudos aprofundados diante da efemeridade que caracteriza a arte a manifestação de rua. E ainda, mostrar a transformação de um espaço urbano, como paisagem cultural. Outro aspecto que merece destaque e é assunto para outras discussões futuras é a diversidades de estilos e linguagens manifestas que caracterizam diferentes perfis de autores e artistas marcando territórios no mesmo espaço apropriando-se dele pela intervenção urbana.

Contar a história de um lugar, relacionando pessoas, modos de fazer, pensar e se expressar, contribui com a conscientização do seu valor de origem na sociedade em uma escala global, tornando aquela prática sustentável do ponto de vista social e cultural além de dar uma sustentação maior para inovações, transformações. Ganem (2016) defende que a perspectiva do design vem justamente ajudar nessa complexa tarefa de mediar a produção e consumo, tradição e inovação, qualidades locais e relações globais.

\section{Referências}

ARCHER, Michael. Arte contemporânea: uma história concisa. São Paulo: Martins Fontes, 2001.

CAMINHA, C.; FURTADO, V.; VASCONCELOS, E.; AYRES, L. Uma ferramenta de autoria para criação de mapas colaborativos para aplicações em egov 2.0. Em Anais do XXX CSBC 2010 - WCGE, II Workshop de Computação Aplicada em Governo Eletrônico. Minas Gerais, 2010.

CASTELLS, Manuel. A galáxia da Internet: reflexões sobre a internet, os negócios e a sociedade. Rio de Janeiro: Jorge Zahar Ed., 2003.

FALCÃO, Manuela. Ocupe.art: uma plataforma colaborativa como ferramenta de ressignificação de espaços. Porto Alegre: 2014.

GANEM, Márcia. Design Dialógico: gestão criativa, inovação e tradição. Estação das Letras e Cores, São Paulo, 2016.

JAYME, Juliana Gonzaga; TREVISAN, Eveline. Intervenções urbanas, usos e ocupações de espaços na região central de Belo Horizonte. Civitas, Porto Alegre v.12, n.2, 2012, p.359-377.

LEMOS, André. Mídia locativa e território informacional. In: ARANTES, P., SANTAELLA, L. (Ed.).

Estéticas tecnológicas: novos modos de sentir. São Paulo: EDUC, 2008. p. 207-230. 
LUCHIARI, Maria Tereza Duarte Paes. A (re)significação da paisagem no período contemporâneo. CORREA, Roberto; ROSENDAHL, Zeny (Org.). In: Paisagem, imaginário e espaço. Rio de Janeiro, EdUERJ, 2001.

RAFFESTIN, C.. Por uma geografia do poder. Trad. Maria Cecília França. São Paulo: Ática, 1993. RIBEIRO, José Carlos; LIMA, Leonardo Branco. Mapas colaborativos digitais e (novas) representações sociais do território: uma relação possível. Ciberlegenda: Revista do Programa de Pós-Graduação em Comunicação da Universidade Federal Fluminense, n. 25, 2011, p. 38-47. (http://www.uff.br/ciberlegenda/ojs/index.php/revista/article/view/469/283)

TUAN, Y. Espaço e lugar: a perspectiva da experiência. São Paulo: DIFEL, 1983. 